\title{
The Center for Regional and Tribal Child Welfare Studies: Reducing disparities through indigenous social work education
}

\author{
Wendy Haight $^{\mathrm{a}, *}$, Cary Waubanascum ${ }^{\mathrm{a}}$, David Glesener ${ }^{\mathrm{a}}$, Priscilla Day ${ }^{\mathrm{b}}$, Brenda Bussey ${ }^{\mathrm{b}}$, \\ Karen Nichols ${ }^{\mathrm{b}}$ \\ ${ }^{a}$ School of Social Work, University of Minnesota, Twin Cities, 1404 Gortner Ave, St. Paul, MN 55108, USA \\ ${ }^{\mathrm{b}}$ Center for Regional and Tribal Child Welfare Studies, Department of Social Work, University of Minnesota, Duluth 1049 University Drive, Duluth, MN 55812, USA
}

\section{A R T I C L E I N F O}

\section{Keywords:}

Disparities

Indigenous

Child welfare

Education

\begin{abstract}
A B S T R A C T
This research addresses one of the most pressing and controversial issues facing child welfare policymakers and practitioners today: the dramatic overrepresentation of Indigenous families in North American public child welfare systems. Effective, inclusive education is one necessary component of efforts to reduce such disparities. Yet recruiting students from various cultural communities to the field and educating white social work students and professionals to practice in culturally responsive ways are ongoing challenges. In this ethnography, we examine an apparently successful model of inclusive education: the Center for Regional and Tribal Child Welfare Studies (the Center) at the University of Minnesota, Duluth, School of Social Work. For over a decade, the Center has graduated Indigenous and non-Indigenous child welfare workers with MSWs now practicing within tribal communities, as well as provided continuing education for child welfare professionals. At the Center, Indigenous scholars and social workers, tribal leaders and their allies design and sustain a model of honoring and integrating Indigenous worldviews with Western social work. Experiential learning - engaging the "heart and head" - is a cornerstone of the Center's educational practices. Students and professional colleagues are approached with a "good heart" as "relatives" with positive intentions. They learn about the spirituality, language, culture and history of Indigenous people. The strengths-based curriculum also includes challenging content on the legacy of genocide and historical trauma on Indigenous families and communities, as well as contemporary laws and policies such as the Indian Child Welfare Act. The educational worldview and practices of the Center provide understanding for social work, generally, and child welfare, specifically, that supports effective practice and policy within diverse communities.
\end{abstract}

\section{Introduction}

In this paper, we report ethnographic research with the Center for Regional and Tribal Child Welfare Studies at the University of Minnesota, Duluth (UMD), School of Social Work (hereafter, "the Center"). We consider the Center as a model of culturally responsive child welfare; that is, practice and policy that are comprehensive, sustainable and effective in particular communities. We specifically explore ways to reduce persistent disparities in the involvement of Indigenous families in public child welfare systems. The Center addresses this issue through educating Indigenous and non-Indigenous MSW students and practicing professionals who will create policy, administer programs and implement child welfare practice. At the Center, Indigenous scholars and social workers, tribal leaders and their allies have worked together for over a decade to design a model of honoring and integrating Indigenous worldviews and Western social work. Indigenous worldviews broadly encompass spirituality and knowledge systems as expressed through language, ceremony, and other traditions and everyday practices. They suffuse the professional education of MSW students and continuing education of child welfare professionals. This model also illuminates the "blind spots" in Western-centered social work educational models and practices, as well as child welfare systems. It promises to provide understanding for social work, generally, and child welfare, specifically, that will contribute to effective practice and policy within our diverse communities; and create collaborations to reduce system barriers to equitable practice.

\footnotetext{
* Corresponding author.

E-mail addresses: whaight@umn.edu (W. Haight), wauba002@umn.edu (C. Waubanascum), dglesene@umn.edu (D. Glesener), pday@d.umn.edu (P. Day), bussey@d.umn.edu (B. Bussey), knichols@d.umn.edu (K. Nichols).
} 


\subsection{Disparities in indigenous Child welfare}

"The ICWA [Indian Child Welfare Act) has mandated culturally appropriate services for over a generation, yet American Indian family systems continue to be under attack by child welfare policy and practice (Red Horse, Martinez, Day, Day, Poupart \& Scharnberg, 2000)."

The Center addresses one of the most pressing and controversial issues facing child welfare policymakers and practitioners today: the dramatic overrepresentation of Indigenous families in North American public child welfare systems. In Minnesota, for example, the disproportionate involvement of Indigenous families in child welfare is reflected at multiple levels of system involvement. Nationally, Indigenous children are 1.6 times more likely to be subjects of alleged maltreatment reports than are white children (Children's Bureau, 2018). In Minnesota, Indigenous children are 5.4 times more likely than white children to be subjects of an allegation of maltreatment in a Child Protective Services (CPS) accepted report. This disproportionality is even higher than that of Black children who are 3 times more likely than white children to be subjects of maltreatment reports (Minnesota Department of Human Services, 2015). Nationally, Indigenous children have the highest rates of out-of-home care with 13 in care per 1000 compared to 9.6 for Blacks, and 4.2 for whites (U.S. Department of Health and Human Services, 2013). In Minnesota, 96.4 Indigenous children per 1000 were in out-of-home care in 2014 compared to 20.0 and 5.5 of Black and white children, respectively. Furthermore, the number of Minnesotan Indigenous children in out-of-home care has increased from 77.7 children per 1000 in 2005, while most other ethnic groups have decreased. Finally, Indigenous children in Minnesota have the highest rates of re-entry into out-of-home placement within 12 months following family reunification $(27.3 \%$ vs $21.7 \%$ for white children). (Minnesota Department of Human Services, 2015).

These disparities in child welfare persist 40 years after the passage of the federal Indian Child Welfare Act (ICWA) of 1978 (U. S. Public Law 95-608). This law was passed at the demand of tribes to reduce the involvement of Indigenous children in the child welfare system, halt the removal of Indigenous children from Indigenous communities, and reclaim and preserve their cultures. It is based on the political status of tribes as sovereign nations, not on race. It focuses on Indigenous family preservation as integral to tribal sovereignty and reparative justice (Red Horse, Martinez, Day, Poupart, \& Scharnberg, 2000). It recognizes that the removal of Indigenous children from their families is devastating not only for those families, but for Indigenous communities as a whole. Maintaining Indigenous children in Indigenous homes or foster homes ensures continuation of Indigenous communities for future generations.

\subsection{Strengths within indigenous communities}

"In the process of conquest it was necessary also to convince their own people that there were no intellectuals or philosophers among these barbarians. ... This denial of thinking among peoples other than Europeans was so great that when these two worlds came together, the people who wrote the history wrote the Indian thinking right out of the history because by the theories of the conquistador, the Indian could not think, a burro cannot think (Mohawk, 1992, p. 25)."

As this quote from John Mohawk suggests, most social work students and child welfare professionals approach Indigenous families without exposure to the worldviews and strengths of Indigenous communities. Without awareness and understanding of cultural strengths, social workers are likely to bring their own biases into practice. Within the dominant U.S. culture, many have experienced a steadfast focus on the supposed deficits of Indigenous families and communities. Such a focus leaves workers with little knowledge of individual, family and community strengths on which to build healing, and negative preconceptions that undermine helping.

Despite colonization, assimilation, and genocide, Indigenous people have retained and transmitted Indigenous worldviews through the oral tradition. There are diverse Indigenous cultures throughout Turtle Island, but there are some widely shared beliefs and practices. In general, Indigenous people view children as a blessing, not only to the family, but also to the community. Traditionally, the community shares in the responsibility for their well-being. If parents are unable, then aunts, uncles, grandparents, cousins or others may provide care for children. Ideally, the approach to helping and healing those who are struggling is non-punitive, and community-based (see Haight, Waubanascum, Glesener, \& Marsalis, 2018; Morrison, Fox, Cross, \& Paul, 2010; Red Horse et al., 2000). Understanding these worldviews is the foundation of culturally responsive child welfare practice and policy.

\subsection{The impact of historical trauma and Ongoing colonialism on families,} communities and social work education

"It is essential that social workers understand the source of what can appear as dysfunctional behavior of Indigenous peoples and families (Tamburro, 2013, p. 2)."

Despite the considerable strengths of thriving Indigenous communities, some families continue to struggle, and may become entangled in Western-centered child welfare systems. Their struggles, however, must be understood within the legacy of genocide, historical trauma (Brave Heart, Chase, Elkins, \& Altschul, 2011) and ongoing colonization (Tamburro, 2013). Historical trauma, that is, the intergenerational trauma from unresolved grief and disruptions to normative, Indigenous child socialization processes, continues to resonate in many communities (Brave Heart et al., 2011). Beginning in the early 1800s and continuing well into the 20th century, U.S. and Canadian governments attempted to forcefully and brutally assimilate Indigenous people. Implementation of official policies severed children from their culture and kinship networks through forced removal from their families, displacement from tribal homelands, and mandatory boarding school attendance (see Adams, 1995; Bussey \& Lucero, 2013). During the U.S. boarding school era of the late 19th through the mid-20th centuries, children were not only deprived of the care, nurturance and protection of traditional tribal child rearing practices, many experienced abduction and then emotional, physical, and sexual abuse in militaristic schools. While some children survived, many died from disease, malnutrition, and harsh conditions (Adams, 1995; Child, 1998; Lomawaima, 1994; Smith, 2004).

Indigenous People throughout Turtle Island continue to grapple with ongoing colonialism in many forms of oppression, violence, and structural racism including within child welfare systems (Brave Heart et al., 2011). The forced separation of children from their families and communities during the U.S. boarding school era continues to affect Indigenous families and communities. The history of government oppression and genocide has undermined Indigenous cultures and created risks for child welfare involvement. Inadequate exposure to Indigenous parenting role models, personal trauma histories, poverty and racism have weakened generations of Indigenous families (see Bussey \& Lucero, 2013). These experiences have seriously damaged both the capacity of many Indigenous parents to trust potentially helpful services from child welfare agencies and staff members (e.g., Horejsi, Craig, \& Pablo, 1992), and the capacity of non-Indigenous child welfare agencies and staff to understand, evaluate and engage in effective services with them.

Ongoing colonization has also continued to affect the relationship of Indigenous people with mainstream, public educational systems (Deloria Jr \& Wildcat, 2001) including schools of social work. During the peak of formal, compulsory Indian education, the federal government used boarding schools to eradicate Indigenous ways of life and knowledge systems and enforce Western values, Christianity, citizenship training, and rudimentary academics necessary for menial jobs (Adams, 1995). This effort has resulted in the erasure of Indigenous knowledge systems from mainstream education systems (Tamburro, 
2013). Hence, recruitment of Indigenous students to social work is challenging, in part, because of the mistrust or disinterest they may feel towards public education systems and the absence of Indigenous content and Indigenous faculty at most universities. Furthermore, non-Indigenous people including social work students and faculty lack the opportunity to learn and connect with contemporary Indigenous people and centuries old Indigenous knowledge and ways of being.

\subsection{Conceptual perspective: An integration of indigenous and Western worldviews}

“... authentic, culturally relevant social work practice involves applying what fits from Western social work and discarding what does not fit (Gray, Coates, \& Hetherington, 2007, p. 57)."

In this paper, we argue that to become culturally responsive, Western social work in general, and child welfare in particular, must "move over" (Dumbrill \& Green, 2008) to make room for diverse understandings of social issues and helping practices. Indigenous people have helped one another for centuries, but the social work profession has been reluctant to recognize Indigenous ways of practice and healing (Coates, Gray, \& Hetherington, 2006; Hart, 1999). In the tradition of mixed methods inquiry (Greene, 2007), we deliberately integrate relevant and compatible worldviews from Indigenous social work to better understand the Center's educational worldview and content; and Western developmental cultural psychology to better understand the educational process. (See foundational scholarship in Indigenous social work by Barreiro, 1992; Bellefeuille \& Ricks, 2003; Deloria Jr \& Wildcat, 2001; Dumbrill \& Green, 2008; Gray, Coates, Yellow Bird, \& Hetherington, 2013; Gray et al., 2007; Gray, Coates, \& Yellow Bird, 2008; Greenwood \& Palmantier, 2003; Hart, 1999; Red Horse et al., 2000; Sinclair, Hart \& Bruyere, 2009; Tamburro, 2013; Weaver, 2014. See foundational scholarship in developmental cultural psychology by Bruner, 1990; Gaskins, Miller, \& Corsaro, 1992; Lave \& Wenger, 1991; Miller, 1997a, 1997b; Miller \& Goodnow, 1995; Miller, Hengst, \& Wang, S.-h., 2003; Rogoff, 1990; Stigler, Shweder, \& Herdt, 1990; Shweder et al., 2006; Vygotsky, 1962; Wertsch, 1985, 1991).

\subsubsection{Indigenous social work worldview}

Indigenous social work is the "development of social work among Indigenous people of the world" (Gray et al., 2008). We consider Indigenous social work as honoring foundational Indigenous worldviews and practices, and then joining them with Western social work in order to achieve culturally responsive social work practice and policy. Indigenous social work requires a deep understanding of Indigenous worldviews including beliefs and practices related to helping relationships that have existed for over thousands of years. In contrast to "parachuting" in social work interventions designed within other cultural groups, Indigenous social work develops relevant, communityguided, community-centered social work curricula and interventions (Greenwood \& Palmantier, 2003). Indigenous worldviews and practices provide the foundation for collaboration with Western-centered social work practices. For example, Greenwood and Palmantier (2003) described a "First Nations Social Work Stream" to educate Indigenous and non-Indigenous students to practice in culturally responsive ways within Indigenous families and communities. They developed a social work education system in partnership with First Nations leaders in Northern British Colombia. The team developed curriculum unique to the desires and needs of the local First Nations communities, and involved them throughout the lifespan of the program (Greenwood \& Palmantier, 2003). Likewise, the Center designs and conducts their educational programs in partnership with local, Anishinaabe communities.

\subsubsection{Developmental cultural psychology worldview}

The process of education is, essentially, a developmental endeavor. The Center is deliberately intervening to shape the development of
MSW students and professionals. Thus, we also approach understanding their educational process sensitized by concepts from developmental cultural psychology. Developmental cultural psychology is an interdisciplinary field that draws primarily on psychology, anthropology, linguistics, and sociohistorical theory. A basic premise is that development occurs in transaction with cultural contexts (e.g., Miller, 1997a, 1997b; Shweder et al., 2006; Stigler et al., 1990). The Center's students and professionals can only be understood within their Indigenous and non-Indigenous cultural contexts. Their understandings of child rearing and the helping process develops, in part, from their everyday experiences raising children and helping those in need in their families and communities. Effective Indigenous education builds upon these cultural foundations of Indigenous students and professionals, and expands upon those of non-Indigenous students and profesionals.

Developmental cultural psychology approaches change throughout the lifespan as a holistic process. Rather than focusing on the impact of cognitive, social or emotional experiences as separate domains of development, for instance, a developmental cultural psychology perspective allows us to focus on the individuals' changing participation within routine, everyday cultural activities. In this study, we focus on the Center's worldview or "cultural model" (e.g., Harkness, \& Super, C. M. (Eds.)., 1996) of Indigenous child welfare education, and how it guides educational practices for shaping the emerging and changing participation of students and professionals in child welfare work.

\subsection{Research questions and approach}

This paper is the first in a series of three papers emerging from the ethnographic study of the Center. The specific research questions addressed in this paper are: What is the Center's underlying educational worldview? How is this educational worldview put into practice? Subsequent papers in this series will address: 1 . How education through the Center is experienced by Indigenous and non-Indigenous MSW students. 2. Participants' perceptions of outcomes of educational and systems change efforts, and their advice to others seeking to strengthen culturally responsive child welfare practices.

Consistent with a holistic perspective of Indigenous social work and cultural developmental psychology, we approach these questions through ethnographic methods. In the current research, relevant concepts of education, collaboration, child maltreatment and effective helping are sufficiently complex that they are unlikely to be fully understood by investigating isolated variables, especially those primarily identified by cultural outsiders.

In addition, an important function of an ethnographic approach is to help us to identify our own cultural blind spots, for example, in Western-centered social work, so that they do not become obstacles to services and designing appropriate policies for culturally diverse communities. Everyone has cultural blind spots, those unexamined, takenfor-granted beliefs and practices within our own families and communities that seem natural and correct (Morson \& Emerson, 1990). When we, as community members, accept particular beliefs and practices, then those beliefs and practices become both known, and invisible. Miller and Cho (2018) refer to this as the "paradox of familiarity." Attention to diverse cultural cases is necessary to expose cultural blind spots in our understandings, and "render the familiar strange" (Miller \& Cho, 2018). Our experience suggests that we can design understandings that are more adequate and policies, programs and practices that are more effective by learning from one another: Indigenous and non-Indigenous educators, practitioners and scholars.

\section{Method}

\subsection{Setting}

The Center for Regional and Tribal Child Welfare Studies is located in the northern third of the state in an area surrounded by Anishnaabe 
tribes. The $2010 \mathrm{U}$. S. Census listed the Indigenous population of Minnesota as $1.1 \%(60,916$ people) of the state population, $11 \%$ higher than the national average of $0.09 \%$. In Minnesota, there are 11 sovereign Tribal Nations. The four Dakota tribes are: the Upper Sioux (Dakota) Community, Shakopee Mdewakanton Sioux (Dakota) Community, Prairie Island Indian Community, and Lower Sioux Indian Community. These Dakota nations are the original inhabitants of the Minnesota area and are currently spread throughout the lower half of the state along the Minnesota and Mississippi rivers. There also are seven Ojibwe Bands including the Bois Forte Band of Chippewa, Fond Du Lac Reservation, Grand Portage Band of Chippewa Indians, Leech Lake Band of Ojibwe, Mille Lacs Band of Ojibwe, Red Lake Band of Chippewa Indians, and White Earth Reservation. These tribes are spread throughout the northern half of the state, many on large lakes (Lake Superior, Upper and Lower Red Lake, Lake Mille Lacs, Leech Lake, Lake Vermillion). In addition, many of the state's urban centers in Minneapolis, St. Paul, and Duluth have Indigenous families and communities from tribes centered in the Dakotas Wisconsin, and Canada.

\subsection{The Center for Regional and Tribal Child Welfare Studies}

The Center was created in 2005. It evolved from various projects and collaborations of the UMD Social Work faculty and tribal communities dating from the 1990s. The purpose was to increase the capacity of tribes in the areas of child and social welfare, and teach Indigenous culture, language, and history. The Center currently administers Title IV-E Child Welfare stipends, educates future and current child welfare professionals, and engages in community and tribal outreach efforts. Through their work, Center staff identifies and addresses system barriers to culturally responsive practice with Indigenous families and communities. Over the years, staff have developed extensive collaborations at the tribal, county, state, and national levels. They have collaborated with universities and states across the U. S. and Canada to strengthen work within and alongside Indigenous communities. Center funding has included major grants from the U. S. Department of Health and Human Services, the State of Minnesota Department of Human Services, Bush Foundation, and Casey Family Programs to research and improve child welfare practice with Indigenous families.

Throughout its history, the Center has been committed to diversifying the child welfare workforce by creating an educational pathway for Indigenous social work students and to strengthening the cultural understandings of non-Indigenous students and professionals. In this ethnography, we focus on the Center's approach to educating the next generation of child welfare workers, and of practicing child welfare professionals.

\subsection{Participants}

Participant interviews included 13 individuals with diverse roles and extended relationships with the Center. They are tribal elders, Center administrators, educators, researchers, Indigenous and nonIndigenous former MSW students and a judge presiding over the ICWA court. Some participants have had multiple relationships with the Center over a period of years. Center staff nominated them as knowledgeable about the Center's history and work, and all nominated individuals participated. (See Table 1). Note that with the exception of Professor Priscilla Day, all participant names are pseudonyms to protect their confidentiality.

\subsection{Research team}

Members of this research team have diverse professional and life experiences that enrich and strengthen the credibility of the ethnography. Our methods include a deliberate integration of insider and outsider perspectives, i.e., "creative understanding" as described by
Bakhtin (Morson \& Emerson, 1990). Outsider perspectives are critical for identifying constructs taken-for-granted by insiders (Morson \& Emerson, 1990). Insider cultural knowledge and experiences provide a necessary context for identifying appropriate research questions, crafting culturally appropriate methods and procedures, gaining access to and establishing rapport with participants, and understanding their responses. Team members of Ojibwe, Oneida, and Mohawk heritage provided Indigenous perspectives. Team members also have decades of insider experience in child welfare education and training child welfare professionals in working within Indigenous communities. They also have practiced as child welfare workers, ICWA supervisors, and mental health clinicians. Several team members have held major roles within the Center.

\section{Procedures}

\subsection{Interviews}

We conducted 13, in-depth, semi-structured, audio recorded interviews lasting from one to two hours. The interviews were conducted at sites chosen by the participants and included their places of employment. All interviews were conducted by an Indigenous and nonIndigenous researcher with the Indigenous researcher typically taking the lead. Participants were invited to tell their own stories regarding their involvement with the Center (See Appendix A). Follow up prompts included questions about the Center's cultural and spiritual roots, ways of working with stakeholders (including adversarial ones), and relationships formed and lessons learned from Center involvement and how those affect current work. Following transcription of the interviews, participants were invited to edit the transcriptions to best reflect their thoughts, and communicate any additional ideas.

\subsection{Participant observation}

We conducted participant observations during two of the Center's premiere continuing education events: the Winter and Summer Institutes on Indigenous Child Welfare. The day-long Winter Institute is designed for all interested child welfare workers. The three-day long Summer Institute is for Indigenous child welfare workers and invited guests. (These will be described more fully in the Results). In addition, we travelled to a tribal college, a private college and a county social services center where former MSW students are employed, and the Center. We described participant observations in loosely structured field notes describing physical settings, activities, social interactions and impressions.

\subsection{Document review}

Center staff identified a variety of documents to supplement interviews and observations including a series of booklets published by the Center on Raising healthy American Indian children, educational materials used in continuing education trainings, and Center's website. We collected additional, supplementary materials during participant observations including tribal college publications, and documents from the Winter and Summer Institutes,.

\subsection{Analysis}

Interviews were transcribed verbatim and paralinguistic cues affecting meaning (e.g., joyful or reserved tone) or intensity of emotion (e.g., crying) were systematically noted. Using analytic induction techniques (Schwandt, 2014), Indigenous and non-Indigenous University-based members of the research team read and re-read transcripts to develop a preliminary conceptual framework describing participants' perspectives. Documents and fieldnotes were used to triangulate, contextualize and interpret interviews. A coding system was 
Table 1

Interview participants.

\begin{tabular}{|c|c|c|c|c|}
\hline Name & Center Roles (Listed in sequence, chronologically) & Status & Current Position & Career Level \\
\hline Priscilla & Director and professor & Indigenous & Semi-retired & late \\
\hline Beth & MSW student, center staff & Indigenous & Center Staff & mid \\
\hline Kate & Center staff & Non- Indigenous & Center Staff & mid \\
\hline Donna & MSW student, center staff & Non-Indigenous & Tribal Social Services Director & mid \\
\hline Cory & MSW student, tribal elder & Indigenous & Tribal social worker, Educator & late \\
\hline Jack & Tribal elder and center staff & Indigenous & Retired & late \\
\hline Ellen & Professor & Non- Indigenous & Retired & late \\
\hline Betty & MSW student & Indigenous & Retired & late \\
\hline Jane & MSW student & Indigenous & ICWA supervisor & mid \\
\hline Ed & MSW student, center staff & Non- Indigenous & Researcher & mid \\
\hline Sharon & MSW student & Non- Indigenous & Educator & mid \\
\hline Don & MSW student & Non- Indigenous & Social work PhD Student & late \\
\hline Judge S. & Community partner: Established ICWA court & Non- Indigenous & District Judge & late \\
\hline
\end{tabular}

finalized through discussion with Center-based members of the research team. University-based team members then applied this coding system to interview transcripts resolving any disagreements through discussion.

\section{Results}

\subsection{A strengths-based indigenous worldview suffuses social work education at the Center}

There were many signposts pointing towards the Center's underlying educational worldview. When characterizing the Center, educators, former MSW students and professionals repeatedly used the term "American Indian." Our decision to examine how this worldview suffuses Center teachings was clenched when Dr. Day, a Leech Lake elder, ${ }^{1}$ former director of the Center and semi-retired professor, responded to an e-mail from Wendy: "Lots of programs do training about diversity. What makes us unique is that we focus on American Indian culture and approach the process of training from that lens." During her interview, Dr. Day described her strong desire for "supporting and helping to sustain ages-old [American Indian] wisdom to be used in the current world."

Betty, an elder, former MSW student and semi-retired social worker, characterized the "American Indian" perspective of the Center:

It's [American Indian perspective] the view. It's how you look at the world. There's a different way that we look [at life] because of the experiences we've had walking in this world as Indian people. So, for Indian child welfare, how I look at that-it's very personal. It's not just other people. It's my family. It's my people. And understanding of the historical trauma and the different events... It's a different view from a person from the dominant culture, or from the African American culture, or any other culture, because it's personal. It's our experience.

Ed, a mid career, white male researcher and former MSW student, contrasted the Indigenous perspective of the Center with less integrated approaches to diversity education:

It's the [American Indian] lens that she [Dr. Day] sees everything with and then she does a really nice job of bringing that to the Center so it's not like, "Here's some content and we're going to add some pieces about tribal culture" or anything like that. It really like, "This is fundamental to what we do." [For example,] I would say

\footnotetext{
${ }^{1}$ Note that the title of "elder" is a term of deep respect some view as parallel to that of "professor" in the Western world. Many Indigenous people are taught from childhood to respect elders' wisdom and knowledge of traditional values, culture, and language.
}

that about tribal sovereignty. I think that every decision that she made as a Center director was really about, "Does this support tribal self-governance?" And I think that's not a lens that a lot of academic institutions have necessarily. But it gets infused when you have that lens.

Beth, an Indigenous woman, has held various positions at the Center beginning as an MSW student. She contrasted the Center's Indigenous perspective with her experience growing up as one of the "underground Indians" in her small town.

Having contact and learning things with elders about how people are energetic beings was very different than what [I was] taught [in majority culture institutions]. I think that has to do with worldview. It means having a lens that looks a certain way. I've got a camera here, and this is what the lens looks like, and so this is the lens that I understood, that I saw through, for the first 16-17 years of my life. And some things happened, and caused that lens to just shift. It's the same lens but it's just got a little bit different focus now. And, I didn't even realize that I could adjust the lens and I could see way more. I didn't even know I couldn't see clearly out of that lens. So, part of that lens [is] looking for the humanity in everyone, looking for the divinity in everyone, looking for some common ground, personally, as a human.

Deeply rooted in this Indigenous worldview is a respect for cultural and spiritual strengths. This strengths perspective was apparent in many contexts. At the Summer Institute, for instance, Betty instructed the group, "It's really important to look around and see successful Indian people and how their resilience keeps them going. You can't only know people on your case load." A speaker went on to decry what she termed "genocide porn." She adamantly resisted defining her people just through "horrible stories" that evoke pity and connote weakness. "[I don't want people to say], Oh, those poor Indians."

In describing the early research on Indigenous culture, child rearing and approaches to child welfare that laid the groundwork for the Center, Dr. Day explained:

We started, "What does it take to raise healthy Anishinabe kids?" research. So we went out and interviewed elders about raising healthy Indian kids. I think our very first place we went was Bois Forte and we actually went where the elders were gathering, so we went to the Elderly Nutrition Program lunch and met with folks before lunch and just had them talk. So that ended up generating some resources we put together. I think one of the things that academia has been good at - I don't mean that in a good way - is really pointing out all the deficits in our community and so people really wanted us to focus on strengths. And again, people were very gracious about talking with us about their experience with education 
-which wasn't very positive - but also part of why we want to do the Culture and Language Institute [for Indigenous students] was to lift up the really deep cultural beliefs that are embedded in our language and ways of knowing. And to be able to work with elders who were gracious enough to come in and talk with us about the strengths in our communities. And then our work, our research, around what does it take to raise a healthy Anishinabe kid. Most people look at all the bad things, and so we wanted to focus on the strengths.

One of the products of these efforts included several illustrated booklets distributed through the Center and published by the University of Minnesota Duluth Department of Social Work on traditional teachings around raising healthy Indigenous children and approaches to child welfare.The Center's publication, "Using the Seven Traditional Teachings to Raise Healthy Anishnaabe Children" (n.d.) makes clear its strengths-based approach to Indigenous families and communities:

This booklet was developed with the hope of bringing awareness to the community of the beauty and strength that the Leech Lake Band of Ojibwe holds in its children and families. We wanted to share how the Seven Teachings are being lived out with the people and are keeping our communities connected and united. Through our children, families learn to build community bonds that will be there to support them through happiness and through hardship. They learn love, wisdom, humility, respect, courage, honesty, and truth. It is our belief that this legacy of following the Seven Teachings will carry on for generations to come.

Some of the ways in which a strengths-based, Indigenous worldview is instantiated in the Center's educational practices are apparent in: 1) the Indigenous curriculum and how it is designed, 2) how learners are approached, and 3) how content is delivered.

\subsubsection{Designing indigenous curriculum: Ongoing partnerships with tribal communities and respected elders}

Dr. Day underscored the importance of involving tribal communities in designing and delivering the curriculum. In describing the development of the Center, she reflected:

I think one of the things that I really wanted us to do was to go out into the tribal community and say, "What do you think is important for students to know?" "What are the issues that we are struggling with in our communities?" "How, really, can the University be of service?" And I think you are aware of the history of boarding schools and the history of education and the devastating impact it had in tribal communities. So, I expected to be met with a lot of distrust and was kind of blown away at how gracious people were and how they thanked us for asking them what they wanted.

During our interview with Jack, he reflected on his experiences in the design of the Center's curriculum:

I remember being with an elder and he was really knowledgeable and people were asking him like the simplest questions. And he just took his time and turned everything to a real great teaching moment. I think that's one way to be. And so when I brought my students in I wanted to make sure I said, "Ask me anything. I won't get angry. I won't get upset. You know there isn't anything too trivial."

Jack went on to provide a definition of "elder" (ending on a humorous note) in response to Wendy's question: "What does it take to be an elder?"

You know I have a nephew. He must be 10 years younger than I am. I think for the last 20 years I have been calling him an elder. He knows the language. He knows an awful lot about spirituality, sacred songs, and all that information he has. I see him as an elder. So it doesn't have really anything to do with the age so much. Typically, the elders are older, but it's how much information and knowledge they have, to be an elder. If you go through life without any of that, then you're just an old Indian [laughter].

Respect for elders and a valuing of what they taught also was apparent in the responses of the non-Indigenous learners. Ellen, a white woman and retired professor, described how respect for elders affected her and her own mother.

Priscilla invited my partner and I to come [to event at Leech Lake] and we brought my mother and it was right after my dad had died. So she was in her 80's and we brought her from Minneapolis and drove her up to Walker, and she had a really profound experience. And of course, what she got was what elders get from Native people, so she was looked after and talked to and she had a wonderful time. It was a very profound experience.

The importance of elders as sources of traditional teachings and wisdom, and the importance of ongoing relationships with them was prevalent in a variety of contexts. When first entering the Tribal College to interview Betty, we encountered near the front door multiple copies of Tribal College Journal of American Indian Higher Education 2/4. Summer 2018 titled the, "Wisdom of the Elders." This issue reflected the respect for elders that many Indigenous people are taught from very young ages. During Winter and Summer Institutes on Indigenous child welfare (described, below), for instance, elders were served lunch first and younger, or other able-bodied, people automatically monitored the gathering to identify and assist elders or others who needed help. The three day "Summer Institute on Indian Child Welfare" began with 2-1/ $2 \mathrm{~h}$ of teachings by an elder who sat before the group and talked while others sat quietly listening.

The influence of the elders also is apparent in the content of the Center's curriculum with its emphasis on Indigenous culture, history, spirituality and language. In discussing what she valued most about her time in the program, Betty remembered:

Weekends we were immersed in learning about Indian traditions, Indian language, and the elders were there to answer our questions in a good way. I think the most valuable thing we took away from that whole experience was the spiritual activities integrated into the coursework. And we went on weekends with elders, familiar elders from the area. We would spend time with the basic language as well as the historical events. We weren't fully immersed in the language, but throughout the program we had that special part of our weekend sessions. And it was so good. All the students were committed to this.

Students, both Indigenous and non-Indigenous, were expected to learn some language; and exposure to Indigenous languages also was present at the Summer and Winter Institutes. Participants emphasized that knowing the language is vital to understanding the culture. They explained that many Indigenous words are not translatable, or lose the intended meaning in translation. The result is a misunderstanding of traditional worldviews and values. Donna, a non-Indigenous tribal child welfare worker and former MSW student at the Center, described her time as an intern with tribal child welfare services:

That was a fascinating learning experience for me being in [tribal community]. [A.] is an elder that graduated from this program with his MSW. When he was in [tribal community] as a director, I was under him and he taught from an Indigenous perspective. So like for the first 6 weeks, he didn't let me do anything. I had to sit and just listen. And when I spoke, I had to speak the language. And so he got me immersed right away in understanding to speak the language. I had to sit and listen and listen and listen. It was really hard and he sat me with different folks in the agency, different elders, elder women and a few gentlemen who would take me out into the community and I learned from them.

At the same time that the Center's curriculum is strengths-based, it is 
unflinching in its recognition of the need to address challenges. Those challenges, however, are contextualized within an historical context of hundreds of years of genocide by the U.S. government, and its legacy of historical trauma. It also includes attempts to enact laws and policies to protect and support Indigenous families and communities. Importantly, students and professionals learn about ICWA, and the Minnesota Indian Family Protection Act (MIFPA). MIFPA is the Minnesota statute that expands portions of ICWA to strengthen the preservation of Tribal identity and capacity to provide guidance regarding the best interest of American Indian children involved in the child welfare system (Minnesota Department of Human Services, 2018).

\subsubsection{Approaching students, colleagues and clients as relatives with positive intentions}

"Good day my relatives. I greet you with a good heart." These words, uttered by a respected elder, opened the 2018, Winter Institute on Indigenous Child Welfare attended by both Indigenous and nonIndigenous child welfare professionals and Center students. They exemplify a central characteristic of the Center's treatment of learners: responding to others as human beings and relatives, first. Throughout the training, elders instructed and interacted with learners, inviting reflection, responding to questions and comments with strength and clarity and showing patience, compassion and respect for the learner.

Treating others as human beings and relatives also extends to colleagues. For instance, during the first meeting between Center educators and staff, and educators and students from the University of Minnesota Twin Cities campus, the Center staff did not invite us to meet on the University of Minnesota Duluth campus or at their professional offices. Instead, they arranged for us to share a meal at a favorite restaurant on the shore of Lake Superior. During that meeting, Dr. Day commented that in forming collaborations, Center staff "found relatives." Wendy subsequently asked her to elaborate what she meant by this during an individual interview:

It's about looking for opportunities to really partner and engage with people in meaningful ways so that we can all do better for our families and our communities. It is making relatives, finding people who have the same passion that we have and finding ways to collaborate and work together on these issues. How I prefer to work is to really have those deep conversations and approach things collaboratively and with that belief that we're all doing the best we can. And we can all do better. Everybody's making a good effort which is very different than going in with suspicion and distrust. You're going to get a different outcome when you're going in with the belief that we all really care about doing a good job, to really begin to understand each other better without feeling like you have to defend yourself. We had some folks from Maine come to our Center to visit us-the folks from the Truth and Reconciliation Commission in Maine. And so we opened with a prayer, an Ojibwe prayer, and then we passed around the shell [a spiritual practice where a shell is passed from person-to-person and the one holding the shell can speak] to just talk about the purpose we each had for being at that meeting and what we hoped we could take away from that. And, so it's really kind of a powerful way to center people to kind of cut through, "I'm doctor so and so and I've done this and that. You know, here we are as human beings. We're all the same no matter what our title is. And we all have this intention to interact with each other as humans. It really sets a different kind of way of communicating and I personally believe that we're inviting the spirits in and they're helping us to have these rich conversations that we otherwise wouldn't have if we weren't making that invitation to them. And we believe, Anishinabe, we're taught that when we offer tobacco and we ask in a good way we will get that spiritual help. And so that's what we try to do in those meetings.

Treating others as well intentioned and as relatives also extends to white students, including when they respond out of privilege. Sharon, an educator and former MSW student, related:

I went for a weekend to visit my family in Grand Forks, who are all big Fighting Sioux fans. They wanted the mascot to stay what it was, and I fought with them all weekend and didn't get anywhere. I was feeling kind of angry and self-righteous, and I remember going to Priscilla's office and saying to Priscilla, "You won't believe this weekend I had. I fought with my family all weekend." And Priscilla said to me in the most kind but firm way she could, "Sharon, this is what I deal with every day." And then, of course because she's Priscilla, she's very kind, she processed that with me. But that was a really important moment. It was such a good example of what white privilege does, and how, even if we kind of have this surface level understanding of these things, it's all embedded in our own experience.

Alums extended these beliefs about how to treat others to their child welfare clients. Betty, now retired, described, "I would approach them as if they were my family. That's how you interact with people. I think that's what the essence of what social work is supposed to be-that you treat everybody as if they're your family."

\subsubsection{Educating the head and heart}

Experiential learning - engaging heart and head - is a cornerstone of how the Center's educational worldview is put into practice. Dr. Day explained:

It is an experience, not just information, that helps to bring around transformation of practice through a better understanding of the strengths within the culture-not just a description of the strengths. When students and others have the opportunity to undergo their own personal and professional transformation, they don't quickly forget and default to "normal" practice.

She elaborated in an example including Indigenous and nonIndigenous students:

I've also invited some of our students to some of our [tribal] community events. Our family does big drum ceremonies in the fall and in the spring. I've had students come over to that, in particular my [non Indigenous] students. And that has been a real eye-opener for people to really come to a ceremony they didn't even know exists. I have had students that come and they just start crying. I remember this one woman, she's like, "I don't even know why I'm crying." I'm like, "Well, you're at a ceremony. You don't have to know why. The drum, that's the heartbeat. And clearly it's impacting you and you just need to go with that and at some point it will make sense to you." So those are the kinds of things, you know, providing people an experience. The other thing is I never assume that just because you are an American Indian, you've had those opportunities. So, that was the cool thing about the Culture and Language Institute [for Indigenous students]. I know there were people that went on to continue to have relationships with those elders they were introduced to that they never otherwise would have had. They just hadn't had the opportunity. And so, I think it's a combination of things. Once again it's the head stuff but it's also some experiential stuff.

Beth valued the traditional teachings she received from an elder:

He said, "The purpose - trying to live in a good way and do things in a good way - is to get us out of our heads and down into our hearts." The way that everything is kind of structured right now is we are just supposed to be up here all the time [touching head]. Always worried. Always planning. Always stuck in time. And he said, "The point of those [traditional] teachings is to get us from up here [touching her head] down into our heart [teaching her chest]. And he said, "When you're living and when you're seeing things from your heart, [you] create energy. And if you're looking at things from 
down here [touching chest], whatever they do, you can hold it in a way and understand it in a different way than if you just look at it up here [touching head]." Another person once said to me, his grandma, who lived to be 106, used to tell him, "The longest journey you'll ever make in your life is from your head to your heart." So I think about those kinds of things and I talk about that when I do training all over the state and training social workers; words that reach the heart really impact people.

Indigenous professors also provided experiences of head and heart education in the classroom. Sharon, a white alum and professor at a liberal arts college, described an experience with an Indigenous professor:

So [professor] put us in small groups, and I did what I always describe as my classic cultural norm, which is I took over, and I made sure that we did exactly what the assignment was. So it was very outcome focused, like, "We're gonna get this done." And I was so proud to know I was ready to talk when she brought us back together, but rather than asking what I expected, which is "What did you come up with?" she said, "Tell me how the process of this group went." And there was an American Indian woman in my group and [professor] asked, "What was your experience?" She said, "Well, I didn't say anything." And she said, "Well, why didn't you say anything?" And she said, "Well, nobody asked." I was operating under my normal presumption, which is that what I have to say is important and so I'm going to say it, versus a norm that would say, I will contribute if it seems like it is going to be of service and somebody asks for that service, which is a very different way to approach group work. And for me, of course, in the moment, I felt some degree of shame. But, we didn't stop at shame in any point of this. We would talk about why we have these normative reactions or behaviors, and how they're all part of our own cultural norms, and how becoming aware of them helps us be more responsive to others and to actually set them aside in practice so we aren't unconsciously putting our values on other people.

\subsection{The institutes as exemplars of the Center's indigenous educational worldview and practice}

Currently, the Center presents Winter and Summer Institutes for child welfare professionals and MSW students. These professional trainings are held at Tribal Casino conference centers on tribal lands in rural MN. Approximately $100-250$ people typically attend. The Summer Institutes originated in 2006 in response to tribal directors expressed need for tribally specific training for their social work staff. This Institute is for Indigenous child welfare professionals and students, and is a 3-day-long gathering. Non-Indigenous people may attend by invitation or permission. Given a growing interest of non-Indigenous people in attending, the Winter Institute was begun in 2011. This institute is open to both Indigenous and non-Indigenous child welfare professionals and MSW students.

The Institutes are emotionally, spiritually and intellectually intense gatherings that exemplify the Center's educational worldview and practice: partner with tribal communities, welcome learners and colleagues as relatives, attend to the historical context and trauma of Indigenous families, and focus on language, spirituality and cultural strengths. In 2018, the research team members attended the Winter and Summer Institutes.

\subsection{Winter Institute, “2018 Annual ICWA Conference," may 8, grand casino, Hinckley $M N$}

The conference was especially well attended by approximately 250 Indigenous and non-Indigenous child welfare professionals. As described in Wendy's fieldnotes:
The conference opened with a welcome in Ojibwe by an elder from the Mille Lacs Band and a Lakota elder who was "placed out" of her family and community as a child [adopted by a white family]. She set the tone for the day with, "Good morning my relatives." These elders then told their own life stories, including their description of having their cultures stolen, difficulties upon return to their cultures and, ultimately, being able to reclaim their cultures. They emphasized that children belong to the community, and that their wellbeing depends on cultural and spiritual connections within Indigenous communities. These narratives were followed by an Ojibwe prayer and pipe ceremony.

The morning continued with a presentation by two respected elders from California who described their successful work with implementing ICWA. Beth then presented on the historical context of Indigenous families beginning in the pre-colonial era (before 1492) and including genocide, ${ }^{2}$ that is, the intentional, systematic acts taken by the U.S. government to end Indigenous cultures through assimilation and/or death.

The following session focused on historical and contemporary trauma and resilience. Dr. Day emphasized that trauma affects not just the individual, but whole families and community, and that the legacy of historical trauma distorts "who you are and how you feel about yourself." She described that at the time of genocide, Indigenous values were: courage, love, wisdom, respect, truth, humility, and honesty; and that these are the things that bring health and healing. Even in this relatively brief day-long meeting, I was struck by the prominence of spirituality, ceremonies and narratives of personal experience. It felt like a mini immersive experience.

Cary commented in her fieldnotes:

I wish I had had this when I was a student. My MSW was very general, but at least I lived and worked in my [Indigenous] community so I didn't feel disconnected. It was very healing for me as an Indigenous woman to be around other Indigenous people and allies during my stressful time in my current $\mathrm{PhD}$ program. Especially seeing [elder] after so many years and also seeing Jane again.

Jane and I went to her vehicle to smudge ourselves. This probably wouldn't have happened at any other conference. It was very healing: Being at an event where we have respect for our elders and practicing my values, like making sure elders ate first. Being in a learning environment that doesn't ignore, but prioritizes our history, our issues, our culture, our strengths, and our knowledge is empowering and necessary.

\section{4. "Summer Institute in American Indian Child Welfare," July 9, 2018, northern lights casino, Walker, MN}

The welcome letter to participants of the well-attended Summer Institute described that the Institute was "designed to bring together tribal workers in an informal setting to allow for new learning, problem solving, networking and support for the difficult jobs you all do. Through the Institute we also hope to honor the many dedicated and

\footnotetext{
${ }^{2}$ See the United Nation's definition of genocide:

"Article II In the present Convention, genocide means any of the following acts committed with intent to destroy, in whole or in part, a national, ethnical, racial or religious group, as such: (a) Killing members of the group; (b) Causing serious bodily or mental harm to members of the group; (c) Deliberately inflicting on the group conditions of life calculated to bring about its physical destruction in whole or in part; (d) Imposing measures intended to prevent births within the group; (e) Forcibly transferring children of the group to another group."

http://www.un.org/en/genocideprevention/documents/atrocity-crimes/ Doc.1_Convention $\% 20$ on $\% 20$ the $\% 20$ Prevention $\% 20$ and $\% 20$ Punishment $\% 20$ of \%20the $\% 20$ Crime $\% 20$ of $\% 20$ Genocide.pdf
} 
talented American Indians who have committed themselves to improving Indian child welfare...".

Experiential learning for MSW students began the night before the conference, when several engaged in a sweat lodge ceremony with tribal elders. The topic of the first day of the conference was "Sacred children." An elder opened the first day with a prayer in the Ojibwe language, followed by a pipe ceremony. Then attendees were greeted by a respected elder, "Good day my relatives, I greet you with a good heart." Next, an elder from Ontario, a speaker of the Anishnaabe (Ojibwe) language who currently consults on culturally specific trainings and programs with several U.S. universities, sat before the group. He shared teachings and related them to his own life in a clear and direct manner for $2-1 / 2 \mathrm{~h}$ while the audience sat silently listening. His narration included the challenges he faced as an Indigenous youth and young man, and how connecting with his culture helped him to heal, and fundamentally shaped his worldview.

The topic of the second day was "ICWA: Past, present and future." It opened with a song sung in Ojibwe. The speaker discussed that elders are sacred and should be cared for by the younger generations. Then, a staff member of the Center who was moving on to become Director of a local Tribal Child Welfare Program, was gifted with a Big Drum blanket accompanied by prayers, handshakes and hugs from community members and singing in Ojibwe. The program continued with a presentation by visitors from Maine, who were involved in the Maine Wabanaki-State Child Welfare Truth and Reconciliation Commission (the first truth commission in the U.S. to address Indigenous child welfare). Next, Center staff discussed ICWA work in MN and nationally including ICWA curriculum development, and future training needs. The day closed with an Ojibwe song. Day 3 was devoted to a "Welcome Home Ceremony" honoring those impacted by child welfare. Wendy described her experience in fieldnotes:

For me, the conference exemplified the Center's approach to education of the head and heart. For example, during the first evening, guest presenters from Maine invited participants to an experiential activity. This activity was part of a cross-cultural collaborative that focuses on decolonization through truth, healing and change. Staff narrated the history of the Wabanaki people, residents of Maine for 10,000 years before the arrival of the Europeans. These stories were told while we stood on a beautiful piece of fabric art created by Wabanaki artists to represent their land. As the land was stolen by colonists, the fabric was folded and people were pushed closer together. I was gifted by a blanket deliberately infected with small pox and had to leave the group as a representative of those who died of small pox and other European diseases to which natives had no immunity. Others left the "land" because of forced military service and boarding school. The history was relentless. I was struck by one of the staff's use of the term "soul wound." I learned, for instance, that the U.S. government knew that children in boarding schools were hungry, but rather than using resources to feed the children, used the opportunity to study malnutrition. After the experiential learning exercise, which included several white people, we went around the circle to reflect. I was moved by a respected elder who commented that, initially, she did not want to share with whites, especially not white social workers who she viewed a causing horrible pain and loss in her family. She then expressed the belief that there had to have been white people in the past who said, "Why are we killing these people?" and prayed for their children of the future. She believes that those of us (white) people present were here because someone, an ancestor, prayed for us. This was a very moving experience including for the Indigenous people already familiar with the history. Priscilla smudged (passed cleansing sage smoke over) a participant who, at one point, stepped out of the circle and wept. The activity ended with an Ojibwe song, prayer and traditional handshake where each person walks around the circle shaking everyone's hand in turn.

\section{Discussion}

"As Indians we know some things because we have the cumulative testimony of our people. We think we know other things because we are taught in school that they are true. The proper transition in Indian education should be the creative tension that occurs when we compare and reconcile these two perspectives (Deloria, 2001, p. 86)."

In this ethnography, we deliberately sought to create the "creative tension" referenced by Deloria to understand an apparently successful Indigenous model of inclusive education as it relates to ongoing challenges within mainstream social work education. Effective, inclusive education is one necessary component of efforts to reduce disparities in the child welfare involvement of families from communities of color. Yet educating white social work students and professionals to practice in culturally responsive ways, as well as attracting students from various cultural communities to the field, are ongoing challenges. Working in a team of Indigenous and non-Indigenous social workers, we collaborated to articulate the foundational educational worldview and practices of the Center for Regional and Tribal Child Welfare Studies at the University of Minnesota, Duluth School of Social Work. For over a decade, the Center has graduated Indigenous and non-Indigenous child welfare workers with MSWs now practicing within tribal communities, as well as provided continuing education for child welfare professionals.

What has emerged from the ethnography is a strengths-based educational model or philosophy grounded in Indigenous worldviews and practices in existence since before the colonization of Turtle Island, and applied to the education of contemporary child welfare students and professionals within Western dominated institutions. The curriculum is designed and delivered through ongoing partnerships with tribal communities, drawing especially on the wisdom of Indigenous elders and emphasizing the strengths of Indigenous worldviews and practices, especially spirituality and language. It also includes content on the genocide of Indigenous people and its aftermath including historical trauma, continuing colonization and governmental child welfare policies. Educators approach and treat learners and colleagues as "relatives" who are imperfect human beings with good intentions, motivated to do their best and with the potential to develop. Educational practices emphasize experiential learning; that is, engaging the heart as well as the head.

\section{Limitations}

Before considering implications, it is important to acknowledge limitations. Due to the relative brevity of the participant observation, our articulation of the Center's Indigenous educational worldview relied primarily on those aspects of which insiders were consciously aware and able to articulate. In other words, the outsiders on the research team had relatively limited opportunities to identify and raise questions about beliefs and practices that may have been taken-for-granted by insiders. In addition, the scope of this ethnography is limited. We recognize that there are multiple, complex Indigenous cultures that vary from one another and additionally encompass variations within each culture. This ethnography focused on the Center, which is influenced largely by the Anishinaabe worldviews of northern Minnesota. In addition, we recognize that within group variation is essential for a fuller understanding of cultural context, but such variation was beyond the scope of our study. We focused on beliefs and practices shared across participants. We also understand that education, while foundational, is not sufficient to bring about change to child welfare systems in the face of limited resources and political opposition. Strengthening tribal capacity, developing collaborations between tribal communities and county/state child welfare systems, and removing system barriers to effective child welfare practice are other areas addressed by the Center, 
that will be described in our subsequent papers.

\section{Implications: Lessons learned}

The goal of this research is to start a cross-cultural conversation among people from diverse cultural groups that allows us to reflect back on how we engage students, professional colleagues, and clients; and stimulate creative thinking. For example, are there aspects of the Center's Indigenous educational worldview and practices that have implications for increasing the effectiveness of our own, often contentious diversity classes, continuing education workshops, and MSW programs? To what extent does our child welfare work recognize the worldviews, history, perspectives, experiences and practices of clients from various communities? How can non-Indigenous child welfare workers and systems can better support and partner with Indigenous families and communities? Our goal is to understand and communicate what Indigenous scholars and professionals from the Center are "up to" from their perspectives, and to use those understandings to strengthen culturally responsive child welfare. Our goal is not to provide a "roadmap" to Indigenous child welfare scholarship, practice or education, nor is it to critique the Center.

Implications of this research, or "lessons learned" will vary somewhat depending on the social position of the reader. Our cross-cultural conversations focused on lessons pertaining to child welfare education. However, we also learned lessons pertaining to scholarship and practice. Some lessons were common across the research team, while others were relatively more specific to the social positions of individual team members with particular practice experiences, or as Indigenous or nonIndigenous people.

\subsection{Education}

During the course of our ethnography, we became increasingly aware of the Western hegemony of social work education and attentive to how this may undermine efforts to diversify the child welfare workforce through the recruitment and education of Indigenous students. Indigenous students educated in Western dominated institutions carry their Indigenous knowledge with them into this world (Deloria Jr \& Wildcat, 2001). The disconnection between Indigenous with contemporary Western culture requires many Indigenous people to feel as though they must "live in two worlds." In contrast, the Center brings together Indigenous worldviews and practices with Western social work. Indigenous perspectives are honored, and educational events are led by Indigenous social workers, elders and scholars with Indigenous students and professionals as active partners.

We also considered the implications of Western dominated social work education for the education of non-Indigenous students in culturally responsive child welfare practice and policy. As newly trained social workers are prepared to work with diverse individuals, families, and communities, they remain guided by Western ways of knowing that can shape and distort their perceptions of and practice with Indigenous peoples (Tamburro, 2013). To the extent that social work education resides primarily on a Eurocentric foundation, despite its commitment to social justice, it contributes to the ongoing colonization of Indigenous people (Greenwood \& Palmantier, 2003). "Decolonizing" social work requires both the disruption of its Eurocentric worldview and inclusion of other ways of understanding social challenges and helping, including Indigenous social work (Dumbrill \& Green, 2008; Greenwood \& Palmantier, 2003; Tamburro, 2013). The Center provides a pathway to "decolonizing" social work education by honoring and integrating Indigenous knowledge into social work education to support culturally responsive child welfare.

Other schools of social work throughout the U.S. and Canada also have been integrating Indigenous knowledge, guided by Indigenous communities and elders (Greenwood \& Palmantier, 2003). This postcolonial approach to learning and practicing social work includes the understanding and acknowledgment of both historical and ongoing colonialism, and it privileges the "worldviews and cosmo-visions" of Indigenous peoples (Tamburro, 2013). Child welfare professionals can help families by supporting clients' healing from the past through reconnecting to culture and language. For instance, Indigenous and ally social workers have implemented the White Bison program, "Mending Broken Hearts", created to facilitate healing from personal and historical trauma, and historical unresolved grief (whitebison.org).

\subsection{Scholarship}

The Center functions within a Western university through a negotiated fusion of Indigenous and Western worldviews and practices. Taking the Center as a model, we approached our child welfare scholarship sensitized by a deliberate integration of relevant and compatible worldviews from Indigenous social work and Western developmental cultural psychology. Both frameworks view individuals' development across the lifespan as a holistic process that can be understood only within cultural contexts. Culturally responsive, child welfare scholarship, then, requires conceptual frameworks grounded in an understanding of specific cultures, not those simply "parachuted" in from other, typically Western, cultural groups.

For some team members, the ideas from developmental cultural psychology that a fundamental role of scholarship is to illuminate cultural blind spots and "render the familiar strange" was powerful. All ethnographies are, essentially, comparative because the researchers' cultural context forms a backdrop for understanding (Miller \& Cho, 2018). Attention to diverse cultural cases is necessary to expose cultural blind spots in current understandings, and lead to more adequate child welfare scholarship, practice and policy.

For other members of our research team, the Indigenous worldview uniquely underscored the role of the spiritual and communal well-being of children, families and tribes. They identified the role of spirituality and communal helping as blind spots in their Western conceptual frameworks, especially for those families struggling to recover from maltreatment.

\subsection{Practice}

Practice implications are likely to vary depending on one's cultural community of origin, position in practice, etc. As a former supervisor of an ICWA unit, Dave, a white social worker, was struck by the extent to which an Indigenous worldview suffused the narratives and shaped the understandings of Indigenous participants. As he reflected on his practice experience, Dave remembered the intensely negative reactions of many Indigenous family members to white child welfare workers, as well as the defensive reaction of some of those workers. Through this ethnographic research, Dave came to appreciate more deeply what nonIndigenous child welfare workers may represent to Indigenous families. In his role as ICWA supervisor, Dave reflected on the importance of continuing education for his white workers to develop an understanding that Indigenous families may react strongly and negatively to white workers because of who and what they represent, not anything that they have personally done. For Indigenous families, nonIndigenous workers may represent a long history of genocide, including assimilation through child removal. Non-Indigenous workers may engage better with Indigenous families if they can hear the anger without defensiveness and with acknowledgement of this history as well as the strong, nurturing Indigenous parenting which the tribes have wrapped around their communities for millennia.

\footnotetext{
${ }^{3}$ Cosmovisions: "a view of the world and the cosmos, including spirituality" (Tamburro, 2013)
} 


\section{Conflict of interest}

The authors report no conflict of interests.

\section{Interview protocol}

1. Please tell us about your involvement with the Center. (Possible prompts include: When did you become involved? How did you become involved? Why did you become involved?)

2. Please tell us more about your understanding of how the Center came into being.

3. We understand that the Center's approach is deeply, culturally rooted. Please tell us more about this foundation.

4. How has this foundation affected your relationship building, especially with others who have different professional or cultural perspectives?

5. Please tell us more about how the Center works to help stakeholders, some of whom are adversarial, develop new ways to partner.

6. Has one of those stakeholders been particularly helpful to your work? If so, how has this person been helpful?

7. Please tell us about some of the relationships you've formed as a result of your participation in Center projects. (Possible probes include: to what extent has Center participation helped you develop or strengthen relationships with people from different organizations, or tribes? Tell us more about the impact of these relationships on you personally and professionally.)

8. Please tell us more about the role of spirituality in working together. (prompts-have you seen spiritual activities? What kinds of activities have your participated in? In what ways have these activities shaped Center projects? What have these spiritual activities meant for you?)

9. What are some of the lessons you've learned as a result of your participation at the Center?

10. How have these lessons affected the way you go about your work? (Prompts" How have these lessons impacted the way that you approach other professionals? How you approach challenges? How you rally support to address challenges? Allow you to think about issues in new ways?)

11. Given the challenges faced by Indian families involved with child welfare throughout the U.S., others may be interested in using the work at the Center as a model for change in their own jurisdictions. What advice do you have for these individuals?

12. Anything else that you are learning or that you can share with us?

\section{Acknowledgements}

We would like to acknowledge the Indigenous elders and Indigenous and ally social work professionals who graciously shared their stories and wisdom. We look to them for guidance as we continue our work to protect our children and Indigenous cultures into the next seven generations. This report was made possible through funding from the Gamble-Skogmo endowment of the University of Minnesota, School of Social Work.

\section{References}

Adams, D. W. (1995). Education for extinction: American Indians and the boarding schoo experience, 1875-1928. Lawrence: University Press of Kansas.

Barreiro, J. (1992). Indian roots of American democracy. New York: Akwe:Kon Press.

Bellefeuille, G., \& Ricks, F. (2003). A pathway to restoration: From child protection to community wellness. Native Social Work Journal, 5, 23-43.

Brave Heart, M., Chase, J., Elkins, J., \& Altschul, D. (2011). Historical trauma among indigenous peoples of the Americas: Concepts, research, and clinical considerations. Journal of Psychoactive Drugs, 43(4), 282-290.

Bruner, J. S. (1990). Acts of meaning. Vol. 3. Harvard University press.

Bussey, M., \& Lucero, N. M. (2013). Re-examining child welfare's response to ICWA: Collaborating with community-based agencies to reduce disparities for America Indian/Alaska native children. Children \& Youth Services Review, 35(3), 394-401.
Child, B. J. (1998). Boarding school seasons: American Indian families, 1900-1940. Lincoln, NE: University of Nebraska Press.

Children's Bureau (2018). Child Maltreatment 2016. Available from http://www.acf.hhs. gov/programs/cb/research-data-technology/statistics-research/child-maltreatment.

Coates, J., Gray, M., \& Hetherington, T. (2006). An 'ecospiritual'perspective: Finally, a place for indigenous approaches. British Journal of Social Work, 36(3), 381-399.

Deloria, V., Jr., \& Wildcat, D. (2001). Power and place: Indian education in America. Colorado: Fulcrum Publishing.

Dumbrill, G. C., \& Green, J. (2008). Indigenous knowledge in the social work academy. Social Work Education, 27(5), 489-503.

Gaskins, S., Miller, P. J., \& Corsaro, W. A. (1992). Theoretical and methodological perspectives in the interpretive study of children. New Directions for Child and Adolescent Development, 1992(58), 5-23.

Gray, M., Coates, J., \& Hetherington, T. (2007). Hearing indigenous voices in mainstream social work. Families in Society, 88(1), 55-66.

Gray, M., Coates, J., \& Yellow Bird, M. (2008). Indigenous social work around the world: Towards culturally relevant education and practice. England: Ashgate Publishing Limited.

Gray, M., Coates, J., Yellow Bird, M., \& Hetherington, T. (2013). Decolonizing social work New York: Routledge.

Greene, J. C. (2007). Mixed methods in social inquiry. Vol. 9. John Wiley \& Sons.

Greenwood, M., \& Palmantier, M. (2003). Honoring community: Development of a first nations stream in social work. Native Social Work Journal, 5, 225-242.

Haight, W., Waubanascum, C., Glesener, D., \& Marsalis, S. (2018). A scoping study of indigenous child welfare: The long emergency and preparations for the next seven generations. Children and Youth Services Review, 93, 397-410.

Harkness, S., \& Super, C. M. (Eds.). (1996). Parents' cultural belief systems: Their origins, expressions, and consequences. Guilford Press.

Hart, M. (1999). Seeking Mino-pimatasiwin (the good life): An aboriginal approach to social work practice. Native Social Work Journal, 2(1), 91-112.

Horejsi, C., Craig, B. H., \& Pablo, J. (1992). Reactions by aboriginal American parents to child protection agencies: Cultural and community factors. Child Welfare, 71, 329-342.

Lave, J., \& Wenger, E. (1991). Situated learning: Legitimate peripheral participation. Cambridge: Cambridge university press.

Lomawaima, K. T. (1994). They called it prairie light. Lincoln, NE: University of Nebraska Press.

Miller, J. G. (1997a). Culture and the self: Uncovering the cultural grounding of psychological theory. In G. Snodgrass, \& R. Thompson (Eds.). The self across psychology: Self recognition, self-awareness, and the self-concept (pp. 217-231). NY: Academy of Sciences.

Miller, J. G. (1997b). Theoretical issues in cultural psychology. In J. W. Berry, Y. Poortinga, \& J. Pandey (Eds.). Handbook of cross-cultural psychology: Volume 1: Theoretical and methodological perspectives (pp. 85-128). (Revised ed.). Boston: Allyn \& Bacon.

Miller, P. J., \& Cho, G. E. (2018). Self-esteem in time and place: How American families imagine, enact and personalize cultural ideal. New York: Oxford University Press.

Miller, P. J., \& Goodnow, J. J. (1995). Cultural practice: Toward an integration of culture and development. New Directions for Child Development, 67, 5-16.

Miller, P. J., Hengst, J. A., \& Wang, S.-h. (2003). Ethnographic methods: Applications from developmental cultural psychology. In P. M. Camic, J. E. Rhodes, \& L. Yardley (Eds.). Qualitative research in psychology: Expanding perspectives in methodology and design (pp. 219-242). Washington, DC, US: American Psychological Association.

Minnesota Department of Human Services (2015). Minnesota's child maltreatment report. Retrieved from https://www.leg.state.mn.us/docs/2016/mandated/161102.pdf.

Mohawk, J. (1992). The Indian way is a thinking tradition. In J. Barreiro (Ed.). Indian roots of American democracy (pp. 20-29). New York: Akwe:Kon Press.

Morrison, C., Fox, K., Cross, T., \& Paul, R. (2010). Permanency through Wabanaki eyes: A narrative perspective from the people who live where the sun rises. Child Welfare, 89(1), 103-123.

Morson, G. S., \& Emerson, C. (1990). Mikhail Bakhtin: Creation of a prosaics. Stanford University Press.

Red Horse, J. R., Martinez, C., Day, P., Poupart, J., \& Scharnberg, D. (2000). Family preservation: Concepts in American Indian communities. Casey Family Programs: Foundations for the Future.

Rogoff, B. (1990). Apprenticeship in thinking: Cognitive development in sociocultural activity. New York: Oxford University Press.

Schwandt, T. (2014). The Sage dictionary of qualitative inquiry. Thousand Oaks, CA: Sage.

Shweder, R. A., Goodnow, J. G., Hatano, G., LeVine, R. A., Markus, H. R., \& Miller, P. J. (2006). The cultural psychology of development: One mind, many mentalities. In W. Damon, \& R. Lerner (Eds.). Handbook of child development: Vol 1 Theoretical models of human development (pp. 716-792). (6th ed.). Hoboken, NJ: John Wiley \& Sons, Inc.

Smith, A. (2004). Boarding school abuses, human rights, and reparations. Social Justice, 31(4), 89-102.

Stigler, J. W., Shweder, R. A., \& Herdt, G. (Eds.). (1990). Cultural psychology: Essays on comparative human development. New York, NY, US: Cambridge University Press.

Tamburro, A. (2013). Including decolonization in social work education and practice. Journal of Indigenous Social Development, 2(1), 1-16.

U.S. Department of Health and Human Services, Administration for Children and Families, Administration on Children, Youth and Families (2013). Recent demographic trends in foster care. Retrieved from https://www.acf.hhs.gov/sites/default/ files/cb/data_brief_foster_care_trends1.pdf.

Vygotsky, L. S. (1962). Language and thought. Ontario, Canada: Massachusetts Institute of Technology Press.

Weaver, H. N. (2014). Social issues in contemporary native America: Reflections from Turtle Island. Ashgate publishing company.

Wertsch, J. V. (1985). Vygotsky and the social formation of mind. Harvard University Press.

Wertsch, J. V. (1991). A sociocultural approach to socially shared cognition. In L. B. Resnick, J. M. Levine, \& S. D. Teasley (Eds.). Perspectives on socially shared cognition (pp. 85-100). Washington, DC, US: American Psychological Association. 